\title{
FAKTOR YANG MEMPENGARUHI TURNOVER INTENTION PRAMUNIAGA
}

\author{
Ignatius Soni Kurniawan ${ }^{1}$, Husni Tamrin ${ }^{2}$ \\ ${ }^{1,2}$ Fakultas Ekonomi Universitas Sarjanawiyata Tamansiswa \\ Jl. Kusumanegara No. 157, Muja Muju, Umbulharjo, Yogyakarta \\ E-mail: soni_kurniawan@ustjogja.ac.id \\ diterima: 8/7/2019; direvisi: 30/8/2019; diterbitkan: 24/9/2019
}

\begin{abstract}
The purpose of the research is to test the effect of job satisfaction, affective commitment, and work stress on turnover intention. Samples taken were 95 respondents using the Slovin method. Data analysis method using multiple linear regression test. This study found that job satisfaction had no effect on turnover intention, affective commitment had no effect on turnover intention, and work stress has a significant positive effect on turnover intention.
\end{abstract}

Keywords: Job Satisfaction, Affective Commitment, Stress, and Turnover Intention

\section{PENDAHULUAN}

Pramuniaga berada pada posisi terdepan dalam pelayanan di ritel karena berhadapan secara langsung dengan konsumen. Dengan demikian pramuniaga adalah perwakilan perusahaan yang langsung dapat dirasakan perjumpaannya oleh konsumen dalam proses transaksi. Pramuniaga berkontribusi pada pencapaian tujuan peningkatan penjualan dan pemeliharaan hubungan pelanggan. Semakin berpengalaman maka pramuniaga akan semakin menguasai pekerjaannya seperti mampu bersikap ramah secara natural dan menguasai informasi produk, bahkan mampu menghafal pembeli yang selalu datang termasuk produk yang dibelinya. Pada sisi konsumen, faktor ketidakpuasan pada industri jasa umumnya bersumber dari si pemberi layanan. Konsumen yang kecewa seringkali memilih tidak mengulang berbelanja pada toko yang sama apabila ada layanan sejenis lain. Konsumen kecewa juga menceritakan keluhannya kepada orang lain yang menjadi promosi negatif sehingga promosi perusahaan menjadi tidak efektif dan menghambat datangnya konsumen baru. Usaha untuk menarik kembali konsumen kecewa yang meninggalkan perusahaan dengan membangun kepercayaannya lagi umumnya membutuhkan biaya dan usaha yang lebih besar. Mempertimbangkan alasan ini, perusahaan ritel perlu mengembangkan keterampilan pramuniaganya dan melakukan retensi atas pramuniaga yang berkinerja baik. Memang perusahaan juga dapat mengambil keuntungan dengan mengganti-ganti karyawan seperti menghindari peningkatan gaji, menekan pengeluaran tunjangan karyawan, mendapatkan karyawan yang masih muda dan mampu berdaptasi dengan cepat, mendorong fleksibilitas dan perubahan secara cepat, serta keuntungan jangka pendek lainnya. Pada beberapa perusahaan kecil dan menengah fleksibilitas dan turnover yang tinggi seringkali dilakukan sebagai cara dalam jangka pendek agar perusahaan tetap bertahan hidup. Disisi lain dampak negatif dari turnover intention bagi perusahaan adalah perginya karyawan yang berpengalaman dan dibutuhkan waktu yang lama dan mahal untuk merekrut, melatih, mengembangkan dan mempertahankan karyawan baru (Arshad \& Puteh, 2018). Karyawan yang telah 
mengenal seluk beluk perusahaan adalah aset penting untuk mengembangkan perusahaan, dan merupakan proses regenerasi kepemimpinan. Turnover intention merupakan niat karyawan secara sukarela untuk keluar dari organisasi dan mencari pekerjaan pada organisasi lain (Saeed, Waseem, Sikander, \& Rizwan, 2014). Karyawan yang memiliki turnover intention belum berpindah dari organisasi namun akan mengurangi kontribusinya seperti bekerja dengan tidak sepenuh hati, menurunkan kualitas, dan mangkir sebagai akibat dari kekecewaannya. Karyawan yang kecewa namun bertahan karena tidak memiliki pilihan bekerja di tempat lain dapat bertindak kontra produktif atau melakukan perbaikan organisasi untuk menghilangkan penyebab kekecewaannya. Organisasi juga dapat berusaha mempertahankan karyawannya dengan memulihkan kepuasan karyawan. Karyawan dengan turnover intention yang tinggi serta didukung alternatif kesempatan bekerja di organisasi lain yang lebih baik akan keluar dari organisasi. Lebih buruk lagi setelah keluar karyawan tersebut menceritakan keburukan perusahaan kepada orang lain. Keluarnya karyawan baik dapat digantikan karyawan baru dengan pelatihan, namun secara keseluruhan pergantian karyawan yang tinggi secara terus menerus dalam jangka waktu pendek dan perginya karyawan berkinerja baik akan menyebabkan penurunan kinerja pada perusahaan (Ferreira \& Almeida, 2015).

PT. Circleka Indonesia Utama Region Yogyakarta merupakan perusahaan ritel di Indonesia dan memiliki banyak cabang di Yogyakarta. Perusahaan ini mengandalkan pramuniga untuk melayani konsumen pada ritelnya namun juga menghadapi turnover intention dalam hubungan kepegawaiannya.
Tabel 1 Data Pramuniaga Tahun 2017

\begin{tabular}{lcccc}
\hline \multicolumn{1}{c}{ Bulan } & Masuk & Keluar & Jumlah & $\%$ \\
\hline Januari & 21 & 16 & 125 & 12,80 \\
Februari & 17 & 6 & 130 & 4,62 \\
Maret & 15 & 15 & 141 & 10,64 \\
April & 16 & 16 & 141 & 11,35 \\
Mei & 18 & 18 & 141 & 12,77 \\
Juni & 15 & 19 & 141 & 13,48 \\
Juli & 22 & 14 & 137 & 10,22 \\
Agustus & 22 & 20 & 145 & 13,79 \\
September & 27 & 15 & 147 & 10,20 \\
Oktober & 15 & 20 & 159 & 13,33 \\
November & 15 & 12 & 154 & 7,79 \\
Desember & 18 & 25 & 157 & 15,92 \\
\hline Rata-rata & 18,4 & 16,3 & 143,2 & 11,41 \\
\hline
\end{tabular}

Sumber: Data Perusahaan (2017).

Tabel 1 menunjukkan persentase turnover pramuniaga cenderung berfluktuatif dari bulan ke bulan, dan terbesar terjadi pada Desember sebesar $15,9 \%$ dengan rata-rata selama 1 tahun adalah $11,4 \%$.

Turnover karyawan pada dasarnya adalah hal normal namun turnover karyawan perlu dipahami penyebabnya agar tidak menyulitkan pencapaian tujuan perusahaan. Anugrah, Nasution, \& Nazaruddin, (2018) menunjukkan peningkatan turnover karyawan dari $10 \%$ (2014) sampai 15\% (2016) yang terjadi pada beberapa rumah sakit di Binjai Indonesia, turnover dapat terjadi pada berbagai jenis perusahaan dan berbagai industri. Riset ini mengkaji pengaruh yang disebabkan kepuasan kerja (Chen \& Wang, 2019), komitmen afektif (Kumaran, 2018), dan stres kerja (Sewwandi \& Perere, 2017) untuk memahami niat keluar pramuniaga.

\section{TINJAUAN PUSTAKA}

Pada dasarnya terdapat motivasi untuk memenuhi kebutuhan di dalam diri karyawan yang menghalangi pekerja untuk berpikir meninggalkan tempat kerja. Motivasi tersebut dapat meningkat atau melemah yang mempengaruhi kinerja dan kepuasan kerja. Kepuasan kerja menyangkut perasaan positif dan negatif mengenai pekerjaan, jika pramuniaga kecewa maka akan lebih menyukai pindah 
Jurnal Ilmiah Ekonomi dan Bisnis

Vol. 16. No.2, September 2019: 158-167

EISSN : $2442-9813$

ISSN : $1829-9822$

perusahaan, lebih lanjut ketidakpuasan akan mengakibatkan produktivitas yang rendah, naiknya absensi, masalah kesehatan mental dan cepat mengalami kelelahan fisik (Alniacik, Alniacik, Erat, \& Akcin, 2013). Jabeen, Friesen, \& Ghoudi, (2017) telah menemukan bahwa kualitas kerja berdampak menurunkan turnover intention pegawai wanita. Individu yang merasakan kepuasan akan berusaha mempertahankan posisinya agar tetap bertahan di organisasi dan tidak bertindak sebaliknya dengan melepaskan diri dari organisasi sekarang. Namun demikian individu yang merasakan kekecewaan, sakit hati, konflik, pertentangan, tidak cocok dengan perannya, dan apapun yang dirasakan merugikan bila ia bertahan, akan muncul niat keluar jika ada alternatif lain yang memberikan kepuasan lebih. Poon (2013) menunjukkan hubungan erat antara kepuasan kerja dan turnover, dan masalah politik penilaian di balik keputusan karyawan untuk meninggalkan pekerjaan mereka. Peneliti terdahulu menemukan bagaimana turnover intention dipengaruhi kepuasan kerja (Poon, 2013; Alniacik, Alniacik, Erat, \& Akcin, 2013; Wickramasinghe, 2013; Mihelic, 2014; Jabeen et al., 2017; Kumar, Jauhari, Rastogi, \& Sivakumar, 2017; Suifan et al., 2017; Chen \& Wang, 2019).

H1: Kepuasan kerja berpengaruh terhadap turnover intention.

Pegawai umumnya akan berusaha untuk memenuhi kewajiban mereka, dengan menunjukkan loyalitas atau kesetiaan yang lebih besar, produktivitas yang lebih baik, dan turnover intention yang kurang, jika mereka merasa bahwa perusahaan memenuhi kewajibannya melalui praktik pengembangan karir yang sesuai melalui promosi, pelatihan dukungan, dan sebagainya. Sebaliknya, jika karyawan merasa terjadi kesenjangan program pengembangan karir maka akan mempengaruhi komitmen afektif yang pada akhirnya dapat menyebabkan pengunduran diri karyawan (Suifan et al., 2017). Komitmen afektif akan meningkat ketika keterlibatan karyawan dalam pekerjaan dibuktikan dengan kepuasan pengalaman seperti kesempatan untuk melakukan pekerjaan yang memuaskan atau kesempatan mengembangkan keterampilan yang bernilai (Meyer, Allen, \& Smith, 1993).

Turnover intention karyawan merupakan konsekuensi dari komitmen organisasi. Turnover intention individu dapat digambarkan sebagai respons psikologis karyawan terhadap kondisi organisasi di tempat bekerja. Riset sebelumnya menemukan adanya dampak terhadap turnover intention yang diakibatkan komitmen (Alniacik, Alniacik, Erat, \& Akcin, 2013; Saeed et al., 2014; Song, 2016).

H2: Komitmen afektif berpengaruh terhadap turnover intention.

Karyawan mengalami stres di kantor adalah hal yang umum dari kehidupan kerja. Stres dapat dipicu oleh perubahan di perusahaan, permasalahan dengan rekan, peningkatan tuntutan, dan kegagalan mencapai tujuan. Stres penting bagi peningkatan produktivitas, tanpa stres maka karyawan kurang tuntutan dan cenderung santai sehingga berkinerja rendah. Namun meningkatnya stres kerja secara berlebihan akan membuat karyawan tidak mampu menanganinya lagi dan berdampak pada kesehatan psikologis serta fisik karyawan dan secara kumulatif berdampak pada kerugian ekonomi perusahaan. Penderita distress dapat meningkat dari nerotik dan semakin parah menjadi psikotik yang harus ditangani karena tidak hanya menurun kinerjanya tapi menjadi sangat negatif perilakunya. Karyawan yang mengalami stres tinggi akan mengalami gangguan psikologis seperti mudah marah, tidak ada motivasi, tidak gembira, dan pesimis. Gangguan fisik berupa sakit dan 
kelelahan, serta gangguan perilaku berupa malas, tidak bertanggungjawab, tidak produktif hingga melanggar hukum. Turnover intention terkait dengan beban di kantor, tekanan, kondisi lingkungan kerja hingga kurangnya kepuasan kerja yang didapat oleh individu karyawan. Penelitian terdahulu menyatakan bahwa stres kerja memiliki pengaruh terhadap turnover intention (Mosadeghrad, 2013; Arshadi \& Damiri, 2013; Sewwandi \& Perere, 2017)

H3: Stres kerja berpengaruh terhadap turnover intention.

\section{METODE PENELITIAN}

Pada dasarnya terdapat motivasi untuk memenuhi kebutuhan di dalam diri karyawan yang menghalangi pekerja untuk berpikir meninggalkan tempat kerja. Motivasi tersebut dapat meningkat atau melemah yang mempengaruhi kinerja dan kepuasan kerja. Kepuasan kerja menyangkut perasaan positif dan negatif mengenai pekerjaan, jika pramuniaga kecewa maka akan lebih menyukai pindah perusahaan, lebih lanjut ketidakpuasan akan mengakibatkan produktivitas yang rendah, naiknya absensi, masalah kesehatan mental dan cepat mengalami kelelahan fisik (Alniacik, Alniacik, Erat, \& Akcin, 2013). Jabeen, Friesen, \& Ghoudi, (2017) telah menemukan bahwa kualitas kerja berdampak menurunkan turnover intention pegawai wanita. Individu yang merasakan kepuasan akan berusaha mempertahankan posisinya agar tetap bertahan di organisasi dan tidak bertindak sebaliknya dengan melepaskan diri dari organisasi sekarang. Namun demikian individu yang merasakan kekecewaan, sakit hati, konflik, pertentangan, tidak cocok dengan perannya, dan apapun yang dirasakan merugikan bila ia bertahan, akan muncul niat keluar jika ada alternatif lain yang memberikan kepuasan lebih. Poon (2013) menunjukkan hubungan erat antara kepuasan kerja dan turnover, dan masalah politik penilaian di balik keputusan karyawan untuk meninggalkan pekerjaan mereka. Peneliti terdahulu menemukan bagaimana turnover intention dipengaruhi kepuasan kerja (Poon, 2013; Alniacik, Alniacik, Erat, \& Akcin, 2013; Wickramasinghe, 2013; Mihelic, 2014; Jabeen et al., 2017; Kumar, Jauhari, Rastogi, \& Sivakumar, 2017; Suifan et al., 2017; Chen \& Wang, 2019).

H1: Kepuasan kerja berpengaruh terhadap turnover intention.

Pegawai umumnya akan berusaha untuk memenuhi kewajiban mereka, dengan menunjukkan loyalitas atau kesetiaan yang lebih besar, produktivitas yang lebih baik, dan turnover intention yang kurang, jika mereka merasa bahwa perusahaan memenuhi kewajibannya melalui praktik pengembangan karir yang sesuai melalui promosi, pelatihan dukungan, dan sebagainya. Sebaliknya, jika karyawan merasa terjadi kesenjangan program pengembangan karir maka akan mempengaruhi komitmen afektif yang pada akhirnya dapat menyebabkan pengunduran diri karyawan (Suifan et al., 2017). Komitmen afektif akan meningkat ketika keterlibatan karyawan dalam pekerjaan dibuktikan dengan kepuasan pengalaman seperti kesempatan untuk melakukan pekerjaan yang memuaskan atau kesempatan mengembangkan keterampilan yang bernilai (Meyer, Allen, \& Smith, 1993).

Turnover intention karyawan merupakan konsekuensi dari komitmen organisasi. Turnover intention individu dapat digambarkan sebagai respons psikologis karyawan terhadap kondisi organisasi di tempat bekerja. Riset sebelumnya menemukan adanya dampak terhadap turnover intention yang diakibatkan komitmen (Alniacik, Alniacik, Erat, \& Akcin, 2013; Saeed et al., 2014; Song, 2016). 
Jurnal Ilmiah Ekonomi dan Bisnis

Vol. 16. No.2, September 2019: 158-167

EISSN : $2442-9813$

ISSN : $1829-9822$

$\mathrm{H} 2$ : Komitmen afektif berpengaruh terhadap turnover intention.

Karyawan mengalami stres di kantor adalah hal yang umum dari kehidupan kerja. Stres dapat dipicu oleh perubahan di perusahaan, permasalahan dengan rekan, peningkatan tuntutan, dan kegagalan mencapai tujuan. Stres penting bagi peningkatan produktivitas, tanpa stres maka karyawan kurang tuntutan dan cenderung santai sehingga berkinerja rendah. Namun meningkatnya stres kerja secara berlebihan akan membuat karyawan tidak mampu menanganinya lagi dan berdampak pada kesehatan psikologis serta fisik karyawan dan secara kumulatif berdampak pada kerugian ekonomi perusahaan. Penderita distress dapat meningkat dari nerotik dan semakin parah menjadi psikotik yang harus ditangani karena tidak hanya menurun kinerjanya tapi menjadi sangat negatif perilakunya. Karyawan yang mengalami stres tinggi akan mengalami gangguan psikologis seperti mudah marah, tidak ada motivasi, tidak gembira, dan pesimis. Gangguan fisik berupa sakit dan kelelahan, serta gangguan perilaku berupa malas, tidak bertanggungjawab, tidak produktif hingga melanggar hukum. Turnover intention terkait dengan beban di kantor, tekanan, kondisi lingkungan kerja hingga kurangnya kepuasan kerja yang didapat oleh individu karyawan. Penelitian terdahulu menyatakan bahwa stres kerja memiliki pengaruh terhadap turnover intention (Mosadeghrad, 2013; Arshadi \& Damiri, 2013; Sewwandi \& Perere, 2017)

H3: Stres kerja berpengaruh terhadap turnover intention.

\section{HASIL DAN PEMBAHASAN}

Riset ini merupakan riset kuantitatif, dengan indikator kepuasan kerja diambil dari Viswesvaran, Deshpande, \& Joseph (1998), komitmen diambil dari Meyer, Allen, \& Smith
(1993), stres kerja diambil dari Roberts, Lapidus, \& Chonko (2016) dan turnover intention diambil dari Angle \& Perry (1981). Pertanyaan menggunakan skala Likert 1 sampai dengan 5. Populasi yang digunakan adalah pramuniaga yang bekerja pada PT Circleka Indonesia Cabang Yogyakarta sebanyak 125 karyawan. Pengambilan sampel menggunakan non-probability dengan incidental sampling atau kuesioner diberikan kepada pramuniaga yang kebetulan ditemui. Pengambilan data dilakukan menggunakan kuesioner secara survey. Rumus Slovin digunakan dalam penentuan ukuran sampel.

$\mathrm{n}=\frac{N}{1+N e^{2}}$

$\mathrm{n}=\frac{125}{1+125.0,05^{2}}$

$\mathrm{n}=95$

Keterangan: $\mathrm{n}=$ Sample size; $\mathrm{N}=$ Populasi; $\mathrm{E}=$ Nilai presisi (tingkat kepercayaan $95 \%$ maka e 5\%).

\section{KESIMPULAN DAN SARAN}

Validitas dan Reliabilitas

Item dinyatakan valid pada nilai $r$ hitung $\geq \mathrm{r}$ tabel $(0,2017)$. Pengujian pearson correlation menghasilkan $\mathrm{r}$ hitung kepuasan kerja $(0,743$ s.d. 0,863), komitmen afektif $(0,77$ s.d. 0,85), stres kerja $(0,821$ s.d. 0,856$)$, dan turnover intention $(0,865$ s.d. 0,899) > 0,2017. Cronbach's Alpha Stand. kepuasan $(0,796)$, komitmen afektif $(0,826)$, stres kerja $(0,857)$, dan turnover intention $(0,906)>$ 0,7 atau instrumen reliabel. Hasil menunjukkan data adalah valid dan reliabel untuk digunakan dalam pengujian lebih lanjut.

Karakteristik Responden

Karakteristik responden pada Tabel 2 menunjukkan lebih banyak karyawan pria (86\%), hampir semua pramuniaga adalah lulusan SLTA (99\%), berdasar usia 
didominasi 21 - 25 tahun (62\%), dan kebanyakan baru bekerja 3-6 bulan $(33,7 \%)$. Secara keseluruhan nampak bahwa perusahaan memprioritaskan pramuniaga masih berusia muda dan dari lulusan SLTA, hal ini diduga karena faktor karakteristik dan spesifikasi pekerjaan. Seorang pramuniaga diharapkan berpenampilan menarik, memiliki fisik yang kuat dan sehat, selalu ramah terhadap konsumen, dan cepat menguasai teknologi informasi.

Tabel 2 Karateristik Responden

\begin{tabular}{|l|c|c|}
\hline \multirow{2}{*}{ Karakteristik } & Keterangan & $\%$ \\
\hline \multirow{4}{*}{ Jender } & Pria & 86 \\
\hline & Wanita & 14 \\
\hline Pendidikan & SLTP & 0 \\
\hline \multirow{4}{*}{\begin{tabular}{l} 
Usia (tahun) \\
\cline { 2 - 3 }
\end{tabular}} & SLTA & 99 \\
\hline \multirow{3}{*}{$\begin{array}{l}\text { Masa Kerja } \\
\text { (bulan) }\end{array}$} & Diploma & 0 \\
\cline { 2 - 3 } & $21-25$ & 1 \\
\cline { 2 - 3 } & $26-30$ & 33 \\
\cline { 2 - 3 } & $>30$ & 62 \\
\cline { 2 - 3 } & $0-3$ & 1 \\
\cline { 2 - 3 } & $>3-6$ & 12,6 \\
\hline
\end{tabular}

Asumsi Klasik

Nilai Kolmogorov-S. Z adalah 1,230 dengan Asy. sig. (2-tail.) 0,097 menunjukkan data residual pada model regresi normal dalam distribusi. Hasil uji Glejser menghasilkan nilai sig. kepuasan kerja $(0,705)$ komitmen afektif (0.759), stres kerja $(1,111)>0,05$ atau tidak signikan yang artinya tidak ada heteroskedastisitas pada model regresi. Hasil uji multikolonieritas menunjukkan nilai tolerance kepuasan kerja $(0,780)$, komitmen afektif $(0,780)$, stres kerja $(0,999)>0,10$ dan nilai Variance Inflation Factor kepuasan kerja $(1,281)$, komitmen afektif $(1,282)$, dan stres kerja $(1,001)<$ 10 yang artinya tidak ada multikolonieritas.

\section{Uji Hipotesis}

Hasil uji t pada Tabel 3 menunjukkan kepuasan kerja memiliki nilai $\mathrm{t}(-1,424)$ dengan sig. $0,158>0,05$ atau tidak signifikan, oleh karena itu H1 ditolak. Komitmen afektif memiliki nilai t $(-0,127)$ dengan sig. $0,899>0,05$ atau tidak signifikan, H2 ditolak. Nilai t $(7,793)$ stres kerja signifikan dengan sig. $<0,000<0,05$ sehingga $\mathrm{H} 3$ diterima.

Tabel 3 Temuan

\begin{tabular}{|c|c|c|c|c|c|}
\hline \multicolumn{6}{|c|}{ Coefficients $^{\mathrm{a}}$} \\
\hline & \multicolumn{2}{|c|}{ Unstd. Coeff. } & \multirow{2}{*}{$\begin{array}{l}\text { Std. C } \\
\text { Beta }\end{array}$} & & \multirow[b]{2}{*}{ Sig. } \\
\hline & $B$ & Std. E & & & \\
\hline (Constant) & 8,238 & 2,871 & & 2,869 &, 005 \\
\hline Kepuasan &,- 241 & 169 &,- 130 & $-1,424$ &, 158 \\
\hline Komitmen &,- 019 &, 148 &,- 012 &,- 127 & ,899 \\
\hline Stres & ,768 & 099 & ,627 & 7,793 &, 000 \\
\hline
\end{tabular}

a. Dependent Variabel: Turnover_Intention

Koefisien Determinasi

Nilai adjusted $R$ square sebesar 0,393 (Tabel 4) artinya pengaruh kepuasan kerja karyawan, komitmen afektif yang dirasakan, dan stres kerja yang dirasakan terhadap turnover intention karyawan adalah sebesar 39,3\%, sementara $60,7 \%$ disebabkan karena variabel lain.

Tabel 4 Koefisien Determinasi

\begin{tabular}{|c|c|c|c|c|}
\hline \multicolumn{5}{|c|}{ Model Summary } \\
\hline Model & $R$ & $\begin{array}{l}R \\
\text { Square }\end{array}$ & Adj. $R S q$. & $\begin{array}{l}\text { Std. Er. of the } \\
\text { Est. }\end{array}$ \\
\hline 1 & $.642^{a}$ & .412 & .393 & 2.832 \\
\hline
\end{tabular}

Turnover intention dinilai responden sebagai berikut: berpikir untuk berhenti dari pekerjaan sebesar 3,44; aktif mencari perusahaan lain sebesar 3,28; merencanakan mencari perusahaan baru dalam setahun sebesar 3,57; mungkin bekerja untuk organisasi lain sebesar 3,46, semua memiliki nilai rata-rata $>3$ dari skala 1 sampai dengan 5. Nilai ini menunjukkan ada niat keluar diatas nilai median (3) yang perlu diwaspadai oleh departemen personalia perusahaan. Skor tertinggi menunjukkan secara jelas karyawan memiliki rencana mencari organisasi yang lebih baik dalam 12 bulan kedepan, yang diikuti indikator kesediaan untuk bekerja 
Jurnal Ilmiah Ekonomi dan Bisnis

Vol. 16. No.2, September 2019: 158-167

EISSN : $2442-9813$

ISSN : $1829-9822$

pada pemberi kerja lainnya.

Temuan menyatakan kepuasan kerja bukan penyebab turnover intention, hasil ini senada dengan temuan penelitian dari (Suputra, Yuesti, \& Sudja, 2018). Kepuasan kerja memiliki ukuran sebagai berikut: puas terhadap kompensasi $(3,83)$; puas lingkungan kerja $(4,04)$; puas peralatan penunjang $(3,89)$; puas jenis pekerjaan $(3,97)$. Hasil perolehan nilai dari indikator kepuasan kerja > 3 yang menunjukkan adanya kepuasan kerja karyawan, namun indikator yang diukurkan tersebut ternyata tidak menjadi penyebab turnover karyawan. Hal ini dikarenakan ada penyebab lain yang lebih kuat sebagai pendorong niat keluar yang pada penelitian ini yaitu stres yang dirasakan pramuniaga.

Komitmen afektif memiliki pertanyaan positif: loyal terhadap organisasi $(3,85)$; bangga pada perusahaan $(3,68)$; memilih bekerja di perusahaan $(3,96)$; dan pertanyaan negatif: tidak merasakan rasa memiliki $(3,72)$. Pada pernyataan positif dijawab dengan ratarata > 3 pada pertanyaan negatif juga dijawab > 3, terlihat kesetiaan, kebanggaan, dan ketepatan memilih perusahaan tidak diimbangi ketiadaan rasa memiliki perusahaan, menunjukkan belum ada komitmen afektif yang kuat. Komitmen afektif tidak berdampak terhadap turnover intention mengkonfirmasi Tnay et al., (2013). Penelitian lebih lanjut dengan menyertakan 3 bentuk komitmen sekaligus yaitu affective, continuance, dan normative perlu dilakukan. Karyawan dengan komitmen affective kuat memilih bertahan di perusahaan karena menginginkannya, karyawan dengan komitmen continuance kuat bertahan di perusahaan karena membutuhkannya, karyawan dengan normative kuat tetap bertahan di perusahaan karena karyawan merasa harus melakukannya (Meyer et al., 1993). Bertumbuhnya pengaruh afektif juga dipengaruhi oleh lama karyawan telah bekerja. Pegawai dengan pengalaman lebih pada bidang pekerjaannya cenderung terpuaskan kebutuhan dasarnya yang dapat mengembangkan komitmen afektifnya untuk lebih kuat dibandingkan karyawan yang kurang berpengalaman (Meyer et al., 1993).

Stres menjadi satu-satunya faktor yang berpengaruh terhadap turnover intention dengan pengaruh positif. Pengaruh positif diartikan semakin stres meningkat maka karyawan semakin tinggi kemauannya untuk meninggalkan perusahaan. Temuan ini mengkonfirmasi riset lebih awal mengenai dampak meningkatnya stres kerja terhadap meningkatnya turnover intention (Arshadi \& Damiri, 2013; Mosadeghrad, 2013; Sewwandi \& Perere, 2017). Pada stres organisasi item pertama: beban berlebihan, memiliki nilai rerata paling tinggi sebesar 3,17 atau paling tinggi. Stressor berikutnya: terdesak terkait waktu $(3,13)$; wewenang tidak cukup $(3,11)$; dan umpan balik atasan kurang (3,09). Nilai ini menunjukkan pramuniaga merasakan stres kerja berada pada kategori cukup. Diduga stres akan beban kerja dirasakan karena 68,4\% pramuniaga masa kerjanya masih setahun atau kurang. Hanya 31,6\% karyawan yang bekerja diatas 12 bulan, menunjukkan minimnya pengalaman, penguasaan, dan intensitas saling mengenal dalam relasi antar pegawai. Rentang masa setahun masih dikategorikan masa pengenalan dan penyesuaian terhadap pekerjaan dan lingkungan baru sehingga sulit untuk dituntut memiliki kinerja tinggi. Dimungkinkan juga faktor stressor bukan karena beban atas pekerjaan yang terlalu berat, namun karena karyawan masih baru dengan lingkungan kerja membuat segala hal perlu dipelajari. Pengenalan atau orientasi kerja dan pemberian peningkatan beban kerja secara bertahap perlu dilakukan agar karyawan baru mampu bertahan dalam masa orientasi kerja. Kondisi tempat kerja dan fasilitas yang nyaman serta teman kantor yang ramah pada pramuniaga baru 
dapat mendukung karyawan beradaptasi dan berkontribusi pada pencapaian tujuan perusahaan.

\section{KESIMPULAN DAN SARAN}

Temuan menyatakan turnover intention secara terpisah tidak dipengaruhi kepuasan dan komitmen. Stres pramuniaga ditemukan sebagai variabel kuat penyebab turnover intention. Dengan demikian perusahaan disarankan mengelola faktor stressor berupa: beban kerja berlebihan, tekanan waktu, kurangnya umpan balik yang jelas, dan kurangnya tanggung jawab untuk penyelesaian tugas. Koefisien determinasi perlu ditingkatkan pada penelitian kedepan dengan melibatkan variabel lain seperti lingkungan kerja, leader member exchange, dan faktor internal seperti emotional intelligence. Memahami penyebabnya turnover intention secara lebih mendalam antara karyawan baru dan karyawan dengan masa kerja lama juga perlu penting dilakukan dalam usaha menjaga sumber daya perusahaan.

\section{DAFTAR PUSTAKA}

Alniacik, E., Alniacik, U., Erat, S., \& Akcin, K. (2013). Does personorganization fit moderate the effects of affective commitment and job satisfaction on turnover intentions? Procedia - Social and Behavioral Sciences, 99, 274281.

https://doi.org/10.1016/j.sbspro.2 013.10 .495

Angle, H. L., \& Perry, J. L. (1981). An Empirical Assessment of Organizational Commitment and Organizational Effectiveness An Empirical Assess- merit of Organizational Commitment and Or-. Administrative Science Quarterly, 26(1), 1-14.
Anugrah, S. U., Nasution, H., \& Nazaruddin. (2018). The Influencing Factors Of Turnover On Nurses In Private Hospitals In Binjai City, Indonesia. Junior Scientific Researcher Journal, IV(November), 49-66.

Arshad, H., \& Puteh, F. (2018). Determinants of Turnover Intention among Employees. Journal of Administrative Science, 12(2), 1-15.

Arshadi, N., \& Damiri, H. (2013). The Relationship of Job Stress with Turnover Intention and Job Performance: Moderating Role of OBSE. Procedia - Social and Behavioral Sciences, 84(2003), 706-710.

https://doi.org/10.1016/j.sbspro.20 13.06.631

Chen, H., \& Wang, C. (2019). Incivility , satisfaction and turnover intention of tourist hotel chefs: moderating e $\mathrm{ff}$ ects of emotional intelligence. International Journal of Contemporary Hospitality, 31(5), 2034-2053.

https://doi.org/10.1108/IJCHM-022018-0164

Ferreira, L. C. de M., \& Almeida, C. B. de A. (2015). Employee Turnover and Organizational Performance: a Study of the Brazilian Retail Sector. Brazilian Business Review, 12(4), 27-56.

Jabeen, F., Friesen, H. L., \& Ghoudi, K. (2018). Quality of work life of Emirati women and its influence on job satisfaction and turnover intention: Evidence from the UAE. Journal of Organizational Change Management, 31(2), 352-370. 
Jurnal Ilmiah Ekonomi dan Bisnis

Vol. 16. No.2, September 2019: 158-167

EISSN : $2442-9813$

ISSN : $1829-9822$

https://doi.org/10.1108/JOCM-

01-2017-0016

Kumar, M., Jauhari, H., Rastogi, A., \& Sivakumar, S. (2017).

Managerial support for development and turnover intention: roles of organizational support, work engagement and job satisfaction. Journal of Organizational Change Management, 31(1), 135-153.

Kumaran, M. M. (2018). The Effect of Affective Commitment, Continuance Commitment, and Normative Commitment on Turnover Intention among Bank Employees. (April).

Meyer, J. P., Allen, N., \& Smith, C. A. (1993). Commitment to Organizations and Occupations : Extension and Test of a ThreeComponent Conceptualization. Journal of Applied Psychology, $78(4)$, 538-551. https://doi.org/10.1037/00219010.78.4.538

Mihelic, K. K. (2014). Work-family interface, job satisfaction and turnover intention A CEE transition country perspective. Baltic Journal of Management, 9(4), 446-466. https://doi.org/10.1108/BJM-092013-0141

Mosadeghrad, A. M. (2013). Occupational Stress and Turnover Intention: Implications for Nursing Occupational Stress and Turnover Intention: Implications for Nursing Management. International Journal of Health Policy and Management, 1(2), 179-186. https://doi.org/10.15171/ijhpm.201 3.30

Poon, J. M. L. (2013). Effects of performance appraisal politics on job satisfaction and turnover. Personnel Review, 33(3), 2004. https://doi.org/10.1108/004834804 10528850

Roberts, J. A., Lapidus, R. S., \& Chonko, L. B. (2016). Salespeople and Stress: The Moderating Role of Locus of Control on Work Stressors and Felt Stress. Journal of Marketing Theory and Practice, 5(3), 93-108. https://doi.org/10.1080/10696679. 1997.11501773

Saeed, I., Waseem, M., Sikander, S., \& Rizwan, M. (2014). The relationship of turnover intention with job satisfaction, job performance, leader member exchange, emotional intelligence and organizational commitment. International Journal of Learning \& Development, 4(2), 242-256.

Sewwandi, D. V. S., \& Perere, G. D. N. (2017). The Impact of Job Stress on Turnover Intention: A Study of Reputed Apparel The Impact of Job Stress on Turnover Intention: A Study of Reputed Apparel Firm in Sri Lanka. 3rd International HRM Conference, (1), 223-229.

Song, L. (2016). A Study of Factors Influencing Turnover Intention of King Power Group at Downtown Area in Bangkok , Thailand. International Review of Research in Emerging Markets and the Global Economy (IRREM), 3(2), 895-908. 
Suifan, T. S., Diab, H., \& Abdallah, A. B.

(2017). Does organizational justice affect turnover-intention in a developing country? The mediating role of job satisfaction and organizational commitment Taghrid. Journal of Management Development, 36(9), 1102-1113.

Suputra, P. M. A., Yuesti, A., \& Sudja, I. N. (2018). The Effect of Work Satisfaction, Organizational Commitment and Workload on Turn over Intention on PT. Bank Rakyat Indonesia (Persero) Tbk Unit Sekanca Denpasar Gajah Mada. RA Journal of Applied Research, 04(08), 1939-1945. https://doi.org/10.31142/rajar/v4i 8.06

Tnay, E., Ekhsan, A., Othman, A., Siong, H. C., Lim, S., \& Lim, O. (2013). The influences of job satisfaction and organizational commitment on turnover intention. Procedia Social and Behavioral Sciences, 97, 201-208. https://doi.org/10.1016/j.sbspro.2 013.10 .223

Viswesvaran, C., Deshpande, S. P., \& Joseph, J. (1998). Job Satisfaction as a Function of Top Management Support for Ethical Behavior: A Study of Indian Managers. Journal of Business Ethics, 17, 365-371.

Wickramasinghe, V. (2013). Impact of time demands of work on job satisfaction and turnover intention Software developers in offshore outsourced software development firms in Sri Lanka. Strategic Outsourcing: An International Journal, 3(3), 246255. 